\title{
Filosofía, historia y política en Patočka: la perspectiva del cuidado y el cuidado como (nueva) perspectiva
}

\author{
Philosophy, history and politics in Patočka: the perspective of \\ care and the care as (new) perspective
}

ANDREA STELLA*

\begin{abstract}
Resumen: Partiendo de las preguntas planteadas por Patočka a propósito de su filosofía fenomenológica de la historia, el objetivo de este artículo es arrojar luz sobre la manera cómo, en la reflexión del autor checo, la política y la historia han venido vinculándose alrededor del problema del cuidado de sí y de los otros, allí donde éste último coincide con la filosofía en cuanto instauración de una inédita (e inaudita) perspectiva de comprensión -acontecimiento por el que, según Patočka, se desencadena (y cabe actualizar cada vez de nuevo) el curso de la historia.

Palabras clave: conmoción; cuidado; punto de vista; vida disidente; vida en la verdad
\end{abstract}

\begin{abstract}
On the basis of the questions raised by Patočka concerning his phenomenological philosophy of history, the aim of this article is to shed light on how, in the thought of the Czech author, politics and history have been linking around the problem of the care of self and others, where the latter corresponds to philosophy as establishment of an original (and unprecedented) perspective of understanding -an event through which, according to Patočka, the course of the history breaks (and it can be always updated).
\end{abstract}

Keywords: upheaval; care; point of view; dissident life; living in truth

\section{Introducción}

En los últimos años de su vida, a partir del estudio de la antigua noción griega de cuidado, Patočka llega a plantear una serie de preguntas que, al vincular las temáticas de su "fenomenología asubjetiva" (concretamente, su descripción de los diferentes movimientos de la existencia humana) a la cuestión ético-política de la responsabilidad (odpovědnost), le llevan a desarrollar un "original" análisis filosófico de la historia.

Recibido: 02/02/2018. Aceptado: 05/05/2018.

* Doctor en Filosofía por la Universidad Autónoma de Madrid e investigador independiente. Colabora con la Universidad Autónoma de Madrid y la Universidad Complutense de Madrid, en las que ha impartido seminarios y ciclos de conferencias sobre Nietzsche, Benjamin, Foucault y Patočka. Su investigación se centra en las áreas de ética y filosofía contemporánea. Sus intereses giran en torno al vínculo entre discurso filosófico y praxis éticas y políticas. Publicaciones recientes: Stella, A., (2018), ¿Qué es filosofía? Foucault entre 'parrhesía' y "cuidado de sí'”, en Cuadernos salmantinos de filosofía, ISSN 0210-4857, no 45, pp. 343-362; Stella, A., (2017), "Foucault y la pregunta por la resistencia entre 'gubernamentalidad' y 'cuidado'. El 'affaire Croissant' y el neoliberalismo", en Bajo palabra. Revista de filosofía, ISSN 1576-3935, ISSN-e 1887-505X, época 2, nº 17, 2017,pp. 269-286. E-mail: andstella@gmail.com 
El elemento de mayor innovación de este análisis estriba no tanto en el gesto que asume como objeto de su pensamiento la historia en su globalidad, como sobre todo en la novedosa perspectiva de la interrogación patočkiana respecto de una cuestión tradicional a partir del siglo XIX ${ }^{1}$, que el autor checo recoge de Husserl, de Heidegger y de los análisis de Arendt sobre la condición humana, a saber: el problema no de determinar el fin de la historia, sino de preguntar por su principio. En relación con esa pregunta tradicional por el origen, ya no se trata, para Patočka, ni de celebrar el despliegue de la historia -entendida como aquel conjunto temporal de sucesos que, en tanto posee un sentido inmanente y accesible a la razón humana, se define por la idea de un progreso (material o moral) como "necesidad férrea"2 de su desarrollo fáctico-, ni de definir el carácter absoluto de la racionalidad europea en cuanto entelequia universal de la humanidad, sino precisamente de lo contrario.

Las novedades aportadas por la perspectiva patočkiana, en efecto, pueden ser identificadas de la siguiente manera: si, en relación con el idealismo husserliano, Patočka trata de dar respuesta a esa pregunta interpretando el mundo natural como mundo pre-histórico (o, en todo caso, haciendo hincapié en el carácter "historial" del Lebenswelt ${ }^{3}$ ), asimismo, respecto de Heidegger y de Arendt, el problema del origen de la historia es planteado por el autor checo insistiendo en el carácter "problemático" y "polemológico" (y "problemático" en tanto en cuanto "polemológico"4) de la libertad -en particular, respecto de Arendt, substituyendo su trilogía de "labor", "work" y "action", por su concepción de los tres movimientos de la existencia humana ${ }^{5}$; y, respecto de Heidegger, destacando en su planteamiento la carencia de un tratamiento de todas esas "otras formas de comportamiento abierto del hombre que no tienen primariamente como sentido y contenido suyo alcanzar la apertura y su trasmisión"6, las cuales, en cambio, Patočka procura abordar mediante la tematización de los dos primeros de esos movimientos, el de arraigo y el de defensa de la vida-.

1 De lo que se trata en el origen de esa pregunta sobre el origen es de establecer qué es la filosofía. Su momento inaugural tiene lugar en el siglo XIX, desarrollándose en el discurso de Hegel y de Zeller, quienes llegaron a identificar la tradición occidental derivada del pensamiento positivo surgido en Grecia en el siglo VI a.C. con "la" filosofía. Se trata de la célebre tesis de Eduard Zeller sobre el "milagro griego", argumentada en su obra monumental Die Philosophie der Griechen in ihrer geschichtlichen Entwicklung dargestellt (1844-1852): el pueblo griego -en el que los intelectuales alemanes del siglo XIX se veían prefigurados- por sus propias especificidades habría elaborado un saber nuevo, absolutamente original, una nueva manera de interrogarse racionalmente sobre el mundo, mientras que las otras civilizaciones de la época se quedaron atrapadas en formas más o menos complejas de superstición o, como mucho, sólo fueron capaces -como en el caso de Cina y de India- de elaborar algunas doctrinas vinculadas a las tradiciones o a las religiones.

2 Cf. Patočka, J. (2016), Ensayos heréticos sobre la filosofía de la historia, trad. de I. Ortega Rodríguez, Madrid: Encuentro, p. 204.

3 Cf. Díaz, Álvarez, J. M. (1995), «J. Patocka: el sentido de la historia, el cuidado del alma y la comprensión de la modernidad»: en Investigaciones fenomenológicas: Anuario de la Sociedad Española de Fenomenología, n. 1, pp. 71-73.

4 Cf. Lasaga Medina, J. (2001), «Sobre la filosofía de la historia de Jan Patočka», en Investigaciones fenomenológicas: Anuario de la Sociedad Española de Fenomenología, n. 3, p. 262.

5 Ricoeur, P. (2016), «Prefacio», en: Patočka, J., Ensayos heréticos sobre la filosofía de la historia, op. cit., p. 22.

6 Patočka, J. (2016), Ensayos heréticos sobre la filosofía de la historia, op. cit., pp. 41-42. 
Henos aquí, por lo tanto, ante aquello que consideramos el carácter original del planteamiento patočkiano en relación con el de sus "maestros" anteriormente mencionados: el autor checo responde a la pregunta tan tradicional por el significado del origen del devenir histórico remitiendo al vínculo entre la noción de conflicto y el núcleo del tercer movimiento de la existencia (el de la apertura) que había previamente teorizado. Es decir: considerando que la posibilidad de la historia y de que ésta tenga un sentido - desde luego, un sentido discontinuo, que no depende de una sola instancia o de un único sujeto histórico- está íntimamente vinculada al constitutivo movimiento de la existencia humana ${ }^{7}$, es decir, a sus fundamentales precariedad y finitud, en la medida en que éstas últimas son los fundamentos reales de esa situación de conflicto en la que, por otra parte, la vida humana se encuentra constitutivamente a existir y sólo a partir de la cual puede (volver a) exponerse más allá de sí misma, a saber: más allá de su propia precariedad y de su constitutiva finitud. En el planteamiento patočkiano sobre la constitución cinética y polemológica de la existencia llegan, por ende, a entroncarse de una manera original tanto sus reflexiones sobre la historia -allí donde el comienzo de ésta última (como veremos) llega a coincidir con el perturbador descubrimiento de la problematicidad y con la "conmoción" (otřesenost) del sentido dado-, como sus investigaciones fenomenológicas, en las cuales llega a expresarse su interpretación en clave ético-política de la consigna fenomenológica para plantear una diferente e inédita perspectiva ${ }^{8}-$.

\section{El surgimiento de la historia}

Ahora bien, el hecho de que la originalidad de la reflexión patočkiana sobre la historia estribe en hacer hincapié en el vínculo entre conflicto real y movimiento de apertura no significa que, para el autor checo, el origen de la historia sólo haya de ser desentrañado "idealizando" o "absolutizando" el supuesto carácter extraordinario e ineludible de ese movimiento existencial y de su alcance "polemológico". En otras palabras, para Patočka no se trata de que lo previo a ese movimiento -respectivamente, el movimiento de arraigo y el de defensa de la vida, los cuales se condensan, en su reflexión sobre la historia, alrededor de las dimensiones de sentido constituidas por el mito, la religión y el arte- no encarne un cambio relevante respecto de la condición prehistórica de la humanidad. El punto de partida de su reflexión es, más bien, otro: aun reconociendo la originalidad de esas manifestaciones de la comprensión humana, Patočka cree que en ellas la existencia aún no ha desarrollado una perspectiva libre (y consciente de sí) respecto del mundo, de los otros y de sí misma. En última instancia, en lo que al mito, a la religión y al arte se refiere, el punto de inflexión respecto de la historia consiste en que, según Patočka, en todas esas dimensiones de sentido la vida humana aún está completamente enfocada en la necesidad básica de conservarse y reproducirse en el mero plano biológico:

7 Cf. Ortega Rodríguez, I. (2009), «Jan Patočka: fenomenología asubjetiva y filosofía herética de la Historia», en Arbor. Ciencia, Pensamiento y Cultura, n. 736 marzo-abril, p. 346.

8 Cf. Esquirol, J. M. (2000), «Tecnica e sacrificio in Jan Patočka», en Jervolino, D. (ed.), L'eredità filosofica di Jan Patočka. Napoli: Cuen, p. 66. 
la historia se da allí donde la vida se hace libre y total. Tiene lugar allí donde la vida edifica conscientemente un espacio para una vida igualmente libre y que no se agota en la mera aceptación; y tiene lugar allí donde la vida -a consecuencia de la conmoción del "pequeño" sentido vital, ése que la aceptación lleva dentro de sí- se decide a intentar de nuevo darse un sentido a la luz de cómo se le muestra el ser del mundo en el que se encuentra emplazada9.

Cuando los eventos y los entes no se revelan conforme al horizonte precomprensivo imperante, y su significado no se acepta sobre la base de la pujanza de la tradición que los revela, sino que empiezan a comprenderse dentro de los márgenes resbaladizos de una inédita perspectiva que los expone a la cuestión de su verdad (y, por ello, los torna ambiguos), allí es donde cabe hablar de historicidad.

Por eso, observa Patočka, en la medida en que es el producto de unas prácticas cuyo origen se remonta a la antigüedad griega, el comienzo de la historia sólo puede pensarse a partir de su vínculo con el "mundo occidental y su espíritu"10. A diferencia de lo que suele admitirse, en efecto, el inicio de la historia no puede coincidir con el surgimiento del fenómeno de la escritura, pues existen casos de "historiografía (historie) sin historia (dějiny)" "11. Los anales antiguos redactados en Asia, Egipto o China antigua son un ejemplo de ello, ya que muestran cómo en aquellas épocas la escritura se practicaba como ejercicio ritual que registra la alternancia de los acontecimientos desde el punto de vista de la vida humana interesada en su conservación. Mientras se limita a vivir en el horizonte sin espesor modulado por el ritmo cíclico de defensa y consolidación de su vida, la existencia es "sin historia": esta última aparece, insiste Patočka, sólo allí donde la vida humana pretende asignarse una perspectiva propia, que no se haya dado y prescrito anteriormente, y que no esté limitada al objetivo de conservar y prolongar su subsistencia biológica:

[...] bajo esta forma -como pregunta radical por el sentido, fundada en la conmoción del sentido vital aceptado ingenua e inmediatamente, la cual trae consigo la pregunta por la verdad e impulsa una y otra vez esta problemática- la filosofía fue desarrollada solamente en su línea occidental. Ésta es la razón decisiva que nos lleva a pensar que la historia, en sentido propio, surgió originariamente como historia occidental, y que mediante complicaciones de su propia problemática fue ella incorporando en sí cada vez a más humanidades hasta hacerse finalmente, en nuestra época, efectivamente universal y planetaria. ${ }^{12}$

Ahora bien, respecto de estas afirmaciones es imposible no percatarse de cómo el planteamiento de Patočka, aun cuando atienda "genealógicamente"13 a las convulsiones que no dejan de sacudir el devenir histórico, resulta ser deudor de la formulación teleológica

9 Patočka, J. (2016), Ensayos heréticos sobre la filosofía de la historia, op. cit., p. 77.

10 Cf.ibid., p. 78.

11 Cf. ibid., p. 63.

12 Ibíd., p. 200.

13 Véase al respecto: Di Martino, C. (2017), «Philosophie et généalogie de l'histoire chez Jan Patočka», en Alter, 25/2017, pp. 173-192. 
que aún define el proyecto husserliano de la Krisis der europäischen Wissenschaften: aunque heréticos, sus Ensayos tratan de descubrir la raíz del $\lambda o ́ \gamma o s$ europeo, de rastrear sus desarrollos y de captar sus derivas perniciosas ${ }^{14}$. Sin embargo, a todo ello creemos que es necesario añadir que Patočka, en su intento de identificar la ratio que opera en el devenir del mundo occidental, propone una reconstrucción histórica mucho más cercana a la declinación genealógica (y trágica) brindada por Nietzsche que a una fenomenología del Espíritu de corte hegeliano. En efecto, tanto para Nietzsche como para Patočka, lo importante no es trazar el itinerario de la historia progresiva de los contenidos de verdad, sino rastrear el devenir histórico a partir de la relación (conflictiva ${ }^{15}$ ) entre vida y verdad. La verdad es un decisivo factor de trasformación en la historia humana: en esta frase podría resumirse uno de los muchos descubrimientos operados por la genealogía de la moral nietzscheana. Pero la afirmación de que la verdad es un agente de trasformación es aquello que también Patočka sostiene cuando, en sus estudios sobre los tres movimientos de la existencia, habla del movimiento de apertura como "movimiento de la verdad". Para el autor checo, de hecho, la verdad nunca coincide con la aprehensión definitiva de un conocimiento, sino con el movimiento de la libertad en cuanto actitud de ininterrumpida problematización que insta a reflexionar sobre esa Noche que toda Luz implica, como fondo y reverso propios de ésta última ${ }^{16}$. En última instancia, en la medida en que es la clave ética que caracteriza la existencia de quienes viven al descubierto, de quienes se interrogan y se dejan interrogar, para Patočka la verdad está íntimamente vinculada a la libertad ${ }^{17}$ y, como observa J. Lasaga Medina, representa "el auténtico 'novum' que provoca con su irrupción la historia"18.

En la distancia entre historia y prehistoria, Patočka halla, entonces, no sólo una confirmación y un terreno donde puede radicalizar su descripción ontológica de la existencia humana en tres movimientos fundamentales, sino también el lugar en que el origen de la historia coincide con el de la filosofía. Si la época prehistórica, en la medida en que sólo está provista de historiografía, se refleja a sí misma mediante un copioso horizonte hecho de relatos, crónicas y mitos, cuya función ritual corresponde a la conservación y la prolongación del eterno retorno del ciclo vital (es decir, respectivamente al primero y al segundo movimiento de la existencia teorizados por Patočka), por otro lado, esa misma época representa tan sólo un momento de transición, a partir de cuya dimensión se desplegará el

14 En esta perspectiva de lectura destacan las consideraciones de Serrano de Haro cuando hace notar que el enfoque patočkiano también parece ser deudor de las formulaciones heideggerianas sobre la historia en cuanto "destino nihilista de Occidente" que "viene a subsumir bajo sí toda coyuntura política y a tragarse, de algún modo, toda responsabilidad histórica. La Fuerza, la voluntad omnímoda de poder, convierte el mal en una circunstancia anónima, indistinta, inimputable": en Serrano de Haro Martínez, A. (2004), «La idea de la solidaridad de los conmovidos en la obra de Jan Patocka », en Villar Ezcurra, A.; García-Baró López, M. (eds.), Pensar la solidaridad, Madrid: Universidad Pontificia Comillas, p. 375.

15 Cf. Lasaga Medina, J. (2001), «Sobre la filosofía de la historia de Jan Patočka», en op. cit., pp. 259-260.

16 Cf. Patočka, J. (2016), Ensayos heréticos sobre la filosofía de la historia, op. cit., pp. 178-192.

17 Come nota Edward F. Findlay en su investigación sobre el valor ético y político que la obra de Patočka puede representar en el contexto posmoderno, "Jan Patočka, like his model Socrates, signaled that there was an unbreakable relationship between politics and philosophy, between truth and the realm of our social being"): en Findlay, E. F. (2002), Caring for the soul in a postmodern age. Albany: State University of New York Press, p. 1.

18 Lasaga Medina, J. (2001), «Sobre la filosofía de la historia de Jan Patočka», en op. cit., p. 262. 
proceso de la aparición de la filosofía -o lo que vale lo mismo para el último Patočka, el

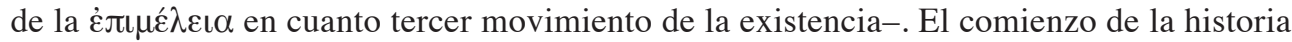
coincide, en efecto, con el desencadenamiento de una "conmoción" (otřesenost) radical sólo sobre cuya base puede desarrollarse la práctica filosófica en cuanto nueva manera de vivir, es decir, en cuanto vida que se constituye como inédito punto de vista sobre el mundo, los otros y sí misma. De pronto, la confianza ingenua que el sentido aceptado brindaba a la existencia, esa certidumbre que implica para la vida humana la confirmación y la justificación del orden de las cosas, se pone en entredicho. Para Patočka, no se trata de que, de buenas a primeras, esa seguridad se pierda completamente, sino que sufre una modificación por la que nace un nuevo punto de vista que, en cuanto tal, la pone a prueba $^{19}$ y a partir del cual se instituye una relación con el mundo basada en la verdad, es decir, una interrogación sobre la totalidad desveladora a partir de cuyo retirarse las cosas se manifiestan ${ }^{20}$. Por este motivo, Patočka afirma que "tienen razón Platón y Aristóteles al

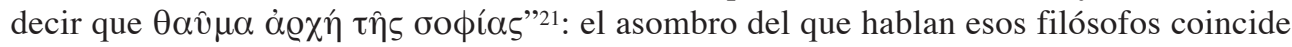
con el llamamiento que inaugura la pregunta filosófica por el sentido, con el estremecimiento que insta la existencia a constituirse como inédito punto de vista sobre sí misma y el mundo, en los términos de una "vida en la verdad".

De ahí también que, para el último Patočka, en tanto en cuanto alude a ese desequilibrio, a esa "crisis" que desencadena el proceso histórico, el tercer movimiento de la existencia humana coincide con la práctica históricamente acontecida del "cuidado del alma", esto es, con la posibilidad de la filosofía en cuanto perspectiva crítica capaz de poner en entredicho y actualizar cada vez de nuevo el sentido mismo de la historia. Claro está, esta apertura de la existencia, este surgimiento en la vida humana de una perspectiva que la expone a la verdad a partir de su arraigo en el mundo (primer movimiento) y su alienación en las cosas (segundo movimiento), representa una potencia que incluso puede no realizarse ${ }^{22}$. No obstante, esa nueva actitud representa un cambio radical, una sacudida y una "conversión gigantesca", "una $\mu \varepsilon \tau \alpha$ vốعv sin precedentes" 23 tanto individual como colectiva que, aún no siendo necesaria a lo largo de la historia, sí decide de su origen, colocándolo en el momento en que se desvincula la existencia humana del orden incuestionable de las cosas, se relaciona con las potencialidades abiertas por la posibilidad de una inédita perspectiva de comprensión $\mathrm{y}$, por ello, se hace responsable (del propio mundo y de su vida) y libre.

19 Cf. Patočka, J. (1983), Platon et l'Europe, trad. fran. de E. Abrams, Lagrasse: Verdier, p. 83.

20 "La filosofía en su conjunto, a decir verdad, no es otra cosa que el despliegue de esta problematicidad, recogida y expresada por los grandes pensadores. Es una lucha por sustraer a la problematicidad algo que emerja de ella para encontrar una nueva tierra firme, pero que en cuanto tal sería nuevamente problematizable. En esto consiste la sabiduría griega originaria; según las palabras de Heráclito - ‘el fuego gobierna todo'- el fuego, es decir, el fulgor que en la noche revela la aurora, pero también vuelve visible la oscuridad; el emerger de todo lo que se halla fuera de las tinieblas a las que toda cosa pertenece y que el fuego únicamente desgarra pero no vence.": en Patočka, J. (1996), «El hombre espiritual y el intelectual», Nombres. Revista de Filosofía, VI, n. 8-9, trad. de D. Tatián, p. 181.

21 Patočka, J. (2016), Ensayos heréticos sobre la filosofía de la historia, op. cit., p. 77.

22 Cf. Patočka, J. (1992), «Was sind die Tschechen», en: Id., Schriften zur tschechischen Kultur und Geschichte, Stuttgart: Klett-Cotta, pp. 29-106.

23 Patočka, J. (2016), Ensayos heréticos sobre la filosofía de la historia, op. cit., p. 116. 
Es por todas estas razones que, afirma Patočka, en tanto en cuanto (abriéndose a la verdad) la existencia se convierte en una vida cuya subsistencia biológica ya no encarna un fin en sí, sino que empieza a existir en función del sentido brindado por la más amplia perspectiva de un mundo abierto y compartido, el inicio de la historia y de la filosofía coincide asimismo con el de la política. En efecto, observa Patočka, es exclusivamente a partir de la dimensión relacional ya establecida por la apertura de diferentes puntos de vista cuando puede configurarse una política, y no viceversa: la política no puede representar un ámbito previamente establecido, sobre cuya base sería posible asentar y describir rigurosamente las relaciones humanas. Antes bien, la política es aquello que se da en la medida en que la existencia se abre, poniéndose "en relación con": en el momento en que la existencia se arroja al mundo, saliendo al encuentro de los otros y yendo más allá de la mera prolongación de su vida biológica, allí surge el espacio de la política -es decir, ese territorio en el que la vida humana, en la medida en que se convierte en "perspectiva-sobre-algo", termina siendo situada "ante la posibilidad de la totalidad de la vida y de la vida en su totalidad"24.

De ahí que, según Patočka, el sentido de la vinculación entre filosofía y política no pueda estar exclusivamente asociado a meros programas económicos o ideologías ${ }^{25}$, sino que haya de desarrollarse sobre todo a partir de una praxis crítica de lo constituido. En tanto en cuanto esta práctica representa el embrión de la vida histórica y política de la humanidad, ningún tratado o argumentación intelectual basada en nuevos principios introducidos desde arriba para suplantar los viejos puede (volver a) fundar una (nueva) política, so pena de correr el riesgo de caer en una renovada metafísica que postula una legalidad universal o unos valores ultraterrenos, ambos ineficaces para una existencia caracterizada como movimiento ${ }^{26}$. Claro está, la política pensada por Patočka no renuncia a determinar los fundamentos comunes que puedan constituir el terreno de encuentro para la disconformidad de estilos y culturas que caracteriza la humanidad post-europea. Sin embargo, a diferencia de lo que ocurre como señala el propio autor checo $^{27}$ - con el planteamiento del problema de una humanidad post-europea que Husserl desarrolla en Die Krisis der europäischen Wissenschaften, allí donde el filósofo alemán se expone al riesgo de eurocentrismo en la medida en que ignora la heterogeneidad de los Lebenswelten y pone la ratio europea como entelequia universal de la humanidad, esos fundamentos no pueden ser sino "negativos". Unos fundamentos que, por lo tanto, no se concretan en un incremento de contenidos, sino en una delimitación de la apertura: una apertura que conserve la "diversidad" de "perspectivas fundamentales" y que permita el "contacto" entre puntos de vista diferentes.

24 Patočka, J. (2004), «¿Qué es la existencia?», en op. cit., pp. 82-83.

25 Cf. Patočka, J. (2016), Ensayos heréticos sobre la filosofía de la historia, op. cit., p. 191. De otra parte, como señala con acierto Ricœur, en Patočka "la política es siempre de un orden distinto al de la gestión económica y la proyección del hombre de la labor; [... la política no tiene otro fin que la vida para la libertad y no la vida para la supervivencia, ni siquiera para el bienestar”: en Ricoeur, P. (2016), «Prefacio», en: Patočka, J., Ensayos heréticos sobre la filosofía de la historia, op. cit., p. 18.

26 Cf., al respecto, Esquirol, J. M. (2011), Los filósofos contemporáneos y la técnica. De Ortega a Sloterdijk, Barcelona: Gedisa, p. 84.

27 Cf. Patočka, J. (2007), «Reflexiones sobre Europa», en: Id., Libertad y sacrificio, trad. de I. Ortega Rodríguez, Salamanca: Sígueme, pp. 218-219. 
Así, cabe afirmar que la filosofía, para Patočka, halla en la política su campo de ejercicio no por la posibilidad de reducir esta última a su propio objeto de reflexión, a fin de desvelar su verdad esencial, sino porque el movimiento de apertura al que la propia realidad política nos insta (es decir, el tercer movimiento de la existencia humana teorizado por Patočka) se despliega como una interrogación permanente de nosotros mismos y de nuestro presente, sobre el fondo de una sensibilidad comunitaria que no oculta las grietas y las sombras de la coexistencia entre las diferentes perspectivas humanas, sino que atisba en ellas otras tantas ocasiones para mantener el pensamiento en una ininterrumpida tensión productiva. Aquello que, en otras palabras, caracteriza el nexo entre filosofía y política adquiere, para Patočka, la forma de la "disconformidad" ética -es decir, de una libertad negativa que se opone a la propensión totalitaria a suprimir la fragilidad de la política y a desactivar las tensiones que recorren la dimensión comunitaria. De ahí que

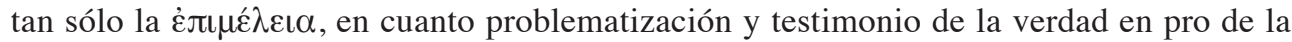
libertad -es decir, en cuanto capacidad de negación de lo establecido y de contemporánea afirmación de un orden (ontológico, ético y político) distinto- pueda representar aquello que, para el último Patočka, es capaz de volver a brindar un (nuevo) sentido a la acción y a la dimensión política a lo largo de la historia:

Se trata de la conmoción de la cotidianidad de los factólogos y rutineros: es hacerles tomar conciencia de que su lugar está de este lado del frente, y no en modo alguno en el de las consignas "diurnas", por muy seductoras que éstas sean. Ellas, en realidad, invitan a la guerra. Así es ya se trate en dichas consignas de la nación, el Estado, la sociedad sin clases, la unidad mundial, o como quiera que puedan sonar todas esas invitaciones susceptibles de ser desacreditadas -y que ya lo han sido- por la fáctica ausencia de miramientos de la Fuerza ${ }^{28}$.

¿Cómo puede configurarse, a través del "cuidado del alma", la libertad de los puntos de vista en una comunidad política? ¿Y qué es esa "alma" de la que hay que ocuparse? Será a partir de estas cuestiones cuando Patočka se vea instado al análisis del dialogo platónico Alcibíades mayor. En el célebre símil platónico del ojo-espejo el autor checo atisba la revelación de la política como dimensión ontológica originaria de la existencia filosófica -la cual, si quiere ser tal, postula la necesidad de múltiples puntos de vista, de los otros considerados como perspectivas distintas-:

Aquí, sin embargo, se subraya al mismo tiempo lo que, en última instancia, está contenido en el propio comienzo de la concepción socrática de lógos; porque sólo la búsqueda, es decir, la búsqueda por medio del lógos, en comunión con la otra persona, puede llevar al autoconocimiento; y esta autocomprensión, esta concentración sobre uno mismo, es algo social, es decir, el germen de la verdadera comunidad, y, por lo tanto, cobra un significado supraindividual: por ende, como resultado, el

28 Patočka, J. (2016), Ensayos heréticos sobre la filosofía de la historia, op. cit., p. 191-192. 
diálogo llega a su cumplimiento en la meditación sobre cómo dar juntos un sentido a la vida en la ciudad [traducción mía, nda] ${ }^{29}$.

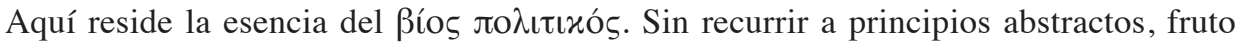
de teorías que prescriben su forma y desarrollo, lo político es caracterizado por Patočka a partir de su determinación ontológica de la existencia, es decir, a partir de su idea de una vida humana constitutivamente arrojada fuera de sí, en medio del mundo de los entes, y, a la vez, expuesta al movimiento de manifestación, es decir, al movimiento del mundo-verdad. Por lo tanto, la lectura en clave política del símil socrático del ojo-espejo brindada por Patočka respalda y confirma su cosmología fenomenológica: si es cierto que, al exponerse al mundo y al responder a los llamamientos de las cosas y de los demás seres, la vida humana deja de ser un fin para sí misma, por otro lado, en este movimiento centrífugo que, de repente, la pone al descubierto, lejos de fragmentarse, la existencia se abre a la posibilidad de vivir con y en pro (o en contra) de los otros -es decir, se convierte en "vida política"-:

Estas consideraciones no deben tomarse como una idealización de la pólis griega. No han de tomarse como si dijéramos que la pólis surgió del espíritu de una entrega desinteresada al "bien común" [...]. El origen de la comunidad política no es un proceso que pueda localizarse con precisión. No cabe atribuirlo a tales o cuales individuos. [...] Ahora bien, lo que resulta distintivo de esta nueva figura y forma de vida es, precisamente, esta circunstancia de que la pólis surja y se mantenga en el seno de luchas externas e internas [...]. Aquí -en unas luchas particulares dentro de un territorio exiguo y con unos medios materiales insignificantes- no sólo surge el mundo occidental y su espíritu. Antes bien, quizás quepa afirmar que surge también la historia universal en general. El espíritu occidental y la historia universal están ligados en su origen. Es el espíritu de la libre donación de sentido, es la conmoción de la vida meramente aceptada y de sus seguridades; y junto a ello, es el surgimiento de nuevas posibilidades de la vida en esta conmoción, esto es, de la filosofía. Ahora bien, el que la filosofía y el espíritu de la pólis se relacionen estrechamente entre sí -de tal manera que el espíritu de la pólis, a la larga, prosiga siempre bajo la figura de la filosofía- hace que este acontecimiento particular, el origen de la pólis, tenga una significación universal. ${ }^{30}$

En cuanto práctica de la verdad, la filosofía (como "cuidado" de sí y de los otros) supone, pues, la cuestión de la libertad, entendida como problema ético-político con-

29 "Zde se však, zároveň zdůrazňuje, co je konečně v samotném počñatku Sókratova pojetí logu obsaženo; jelikož jedině zkoumání, a to zkoumání logem, a to ve spolku s druhým, může přinést sebepoznání, je toto sebepochopení, toto soustředění sebe něčím společenským, je zárodkem pravého společenství, a má tudíž nadindivinduální význam; završuje se tudíž dialog důsledně úvahou o společnem osmyslení, života v obci.". La traducción del texto original checo al castellano se ha llevado a cabo a partir de la traducción italiana recogida en: Patočka, J. (2003), Socrate. Lezioni di filosofia antica, trad. ital. de G. Girgenti y M. Cajthalm (ed. bilingüe checo-italiano), Milano: Bompiani, pp. 383-385.

30 Patočka, J. (2016), Ensayos heréticos sobre la filosofía de la historia, op. cit., p. 78. 
cerniente a la comunidad. El č $\theta$ o $\varsigma$ filosófico, en efecto, plantea directamente, constitutivamente, la cuestión de las relaciones en la $\pi$ ó $\lambda \iota \varsigma$, configurándose como un modo de cuidar de los otros y de la ciudad dentro de una dimensión eminentemente comunitaria. Un cuidado, sin embargo, que -como observan Díaz Álvarez y E. Tassin ${ }^{31}$ - no encuentra, para Patočka, su expresión típica en la conciliación entre filosofía y política, entre verdad y poder, sino en el paradigma de la guerra, del Пó $\lambda \varepsilon \mu \varsigma_{\varsigma}$ heraclíteo $^{32}$, ejemplificado mediante la figura de Sócrates. El tipo de conflicto expresado a través de la vida socrática, en efecto, no implica un acercamiento paulatino y definitivo, sino que plantea la necesidad de una relación crítica entre esas dimensiones antagonistas. Se trata de reafirmar la propia integración en el seno de la comunidad, precisamente introduciendo en ella una diferencia, alimentando así su devenir y su transformación. Se trata, asimismo, de deconstruir la normatividad del poder manteniendo una posición híbrida entre el desdén de la huida solipsista del mundo en común y la reelaboración -ética y políticamente situada- de sus "consignas" 33 . Dicho de otro modo: si la filosofía es cuidado del alma -en cuanto proyecto gnoseológico de apertura a la totalidad y en cuanto asunción de la perspectiva de la propia finitud en relación con un horizonte de sentido que excede la mera consunción de la vida-, por otro lado, ella también se revela, para Patočka, (críticamente) vinculada a la política, entendida como cuidado de la endeble consistencia de una comunidad que acepta el conflicto y la incertidumbre como coyunturas ineludibles. Después de todo, la política (y, gracias a ella, la filosofía) nacieron en el ruedo "agonístico" de la $\pi$ ó $\iota \varsigma$, en la lucha inter pares, en la oposición entre hombres libres: las divisiones y las contraposiciones son su tejido conectivo.

\section{La disidencia como proyecto de subjetivización: la "vida en la verdad"}

Aquí es donde el inicio de la historia coincide con el de la política y con el de la filosofía: el origen de estas tres dimensiones que caracterizaría a la humanidad occidental alude a un mismo momento en el tiempo (y, quizás, en un mismo punto del espacio). Sobre todo, lo que aquí es necesario destacar es el hecho de que, según Patočka, el paso de la pre-historia a la historia, de la no-política a la política, del mito a la filosofía es un punto crucial de transformación que implica la afirmación de la "problematicidad", o lo que vale lo mismo, la aparición de una nueva perspectiva por la que la existencia ya advierte como necesidad inaplazable propia el poner en entredicho el ámbito mundano, es decir, el hecho de desprenderse con coraje, activamente, de su indiferencia (y del incesante ritmo del trabajo que agota sus posibilidades existenciales, sometiéndolas a la ineludible exigencia de conservar su vida biológica) para procurar señalar el nuevo valor en juego en su vida histórica. Al contraponerse a esa disposición tan característica de la humanidad pre-histórica, al separarse de un mundo protegido por la indistinción con lo divino y cerrado en el ritmo reiterado del trabajo, la existencia asume, añade Patočka, las

31 Cf. Díaz, Álvarez, J. M. (1995), «J. Patocka: el sentido de la historia, el cuidado del alma y la comprensión de la modernidad»: en op. cit., p. 77; cf. también Richir, M.; Tassin, E. (eds.), Ján Patoc `ka: philosophie, phénoménologie, politique. Grenoble: Millon, p. 169.

32 Cf. Patočka, J. (2016), Ensayos heréticos sobre la filosofía de la historia, op. cit., p. 79.

33 Cf. ibíd., p. 191. 
características de una "vida en la verdad": es decir, asume los rasgos de una perspectiva que, dejando de "conservar la llama vital", "heretiza" el sentido previamente dado a partir de un inédito vínculo con la verdad, ahora vivida como punto de vista "otro" capaz de poner a prueba y negar lo instaurado:

Ya no se presiente, ya no se predica, ya no se profetiza, ya no se pone la confianza en una "fe inquebrantable"; se ve. Asimismo, este ver no es un mero fijar la mirada en algo respecto de lo que podamos mantener la distancia y que podamos meramente constatar. A la vez que el sentido habido hasta el momento queda conmovido y comprendido como "pequeño sentido", emerge también un ímpetus hacia un nuevo sentido, y lo hace con una urgencia que puede ser vista intelectivamente. Esta patencia no es una evidencia del puro mirar, del puro contemplar. Es un salto hacia un nuevo sentido realizado en la claridad de la situación de problematicidad. ${ }^{34}$

Desde el origen de la historia hasta nuestros días, la posibilidad de una vida "disidente" 35 , es decir, de una "vida en la verdad", de una vida por fin interesada activamente en su ser, sólo es brindada por la praxis ética, filosófica y política del cuidado en cuanto actitud que vive en la perspectiva enigmática de la totalidad, que vive la problematicidad ${ }^{36}$. Sólo al fundarse sobre la base de un "elemento móvil"37, y a partir de una "conmoción" (otřesenost) continua, la existencia llega a adquirir la capacidad de comprometerse con sus elecciones y de hacerse cargo de las consecuencias, involucrándose en un proceso de subjetivización (individual y colectiva) que, en la medida en que la vuelve ética y políticamente activa, le permite plantear nuevos modos de vida. De ahí que, señala Patočka, Sócrates caracterice la comunidad política (pensada como el "lugar propio de la historia"38) como el espacio de despliegue de la práctica epimelética. La $\pi$ ó $\lambda ı \varsigma$, en efecto, no nace allí donde se produce un recíproco reconocimiento inter pares, sino a partir de una convulsión existencial que, en lugar de aislarlos, reúne a los seres humanos y los insta a hacerse conscientes de pertenecer

34 Ibíd., p. 198.

35 No cabe la menor duda de que la palabra "disidencia" tiene un sentido político e histórico muy preciso, en la medida en que se ha utilizado, sobre todo a partir de los años setenta del siglo pasado, para designar justamente el movimiento de oposición intelectual al sistema comunista, tanto en la URSS como en los países del bloque soviético, del que el propio Patočka ha formado parte por su adhesión al manifiesto de la Charta 77. Sin embargo, creemos que hablar de vida "disidente" respecto del concepto patočkiano de "vida en la verdad" resulta muy pertinente porque permite esclarecer otro aspecto original del planteamiento sobre la historia del autor checo, a saber: el hecho de identificar Patočka la conducta "herética" de la disidencia no sólo como el sacrificio ético y político necesario para combatir al totalitarismo comunista del siglo XX, sino, más en general, como ese legado paradigmático de una vida auténticamente libre, abierta y orientada hacia el futuro, que procede del propio origen de la historia (occidental), allí donde ésta última se diferencia de la "prehistoria", eso es, del mundo no-problemático de la repetición y del estancamiento -y, por lo tanto, a partir de cuya posibilidad siempre actual cabe (volver a) influir aún hoy en día en el despliegue de la historia "universal"-. Un legado que, por otra parte, después de su surgimiento "político", según Patočka, habría sido definitivamente profundizado y llevado hasta sus últimas consecuencias por la filosofía en cuanto discurso ontológico portador de un específico estilo ético y político de vida -es decir, por la filosofía en cuanto cuidado del alma (propia y de los otros).

36 Cf. Patočka, J. (1996), «El hombre espiritual y el intelectual», en op. cit., p. 180.

37 Cf. ídem.

38 Cf. Patočka, J. (2016), Ensayos heréticos sobre la filosofía de la historia, op . cit., p. 150. 
a un mismo mundo -es decir, allí donde se genera esa "solidaridad de los conmovidos"39, a partir de una alteración desencadenada por la instauración de una nueva perspectiva (la del cuidado) que, al cuestionar "el sentido habido hasta el momento", reúne las existencias bajo la insignia de la posibilidad de su libertad-. En última instancia, en el problema éticopolítico fundamental que está en la base de la noción de "cuidado" manejada por Patočka, de lo que se trata es de cómo afirmar el tránsito ético y político de la indeterminación sin perspectiva de una vida a la determinación ontológica de la vida; de cómo asegurar el paso desde el acontecer anónimo del Ser a la posición y el ejercicio de un punto de vista (crítico) sobre el mundo; y, finalmente, de cómo dejar centellear, en medio de la impersonalidad uniformadora de la Fuerza, el relámpago de Пó $\lambda \varepsilon \mu$ s que, sobre el trasfondo de una "Noche" ontológica y política, reúne a los seres humanos en la cadena epimelética de la "solidaridad de los conmovidos".

En este sentido, la misma adhesión de Patočka al movimiento de oposición llamado Charta 77, en calidad de portavoz, puede leerse como una puesta en práctica de sus posturas filosóficas. Ese gesto de "conmoción” y "alteración” del orden público ("výtržnictvê") 40 , representó una manera ética, filosófica y política de enfrentarse a lo constituido, de poner en entredicho su estructura, de comprometerse en un proceso de subjetivización que cumpliera con el propósito de llevar al quieto orden de la palabra el relámpago de un punto de vista diferente, de hacer brillar en medio de lo más familiar y cercano la alteridad de una inédita perspectiva sobre su realidad social ${ }^{41}$. Así como el mismo Patočka evidencia en sus escritos sobre la Charta 77, el objetivo de su adhesión ética y política a ese movimiento de oposición era encontrar una acción y un discurso que, capaces de autoridad espiritual, pudieran trastocar el vínculo entre la cotidianidad de la gente que sólo vivía basándose en los hechos -es decir, en la interpretación compartida de los fenómenos- y la fuerza aletúrgica de los poderes -esto es, su capacidad de producir y establecer la verdad de esos fenómenos ${ }^{42}$. En la atmósfera de alienación y fragmentación de sí que el propio Patočka

39 Cf. ibíd., p. 190.

40 Como nos informa Ortega Rodríguez, este término fue utilizado por el régimen comunista de Checoslovaquia para acusar y enjuiciar a unos grupos checoslovacos de música alternativa -acontecimiento a raíz del cual se produjo el movimiento y la declaración en pro de los derechos humanos, conocida como "Charta 77", a la que Patočka se sumó y que le costó la vida: cf. Ortega Rodríguez, I. (2011), Fenomenología, Filosofía de la historia y Política en Jan Patočka, Universidad Pontificia de Comillas (tesis doctoral), p. 368. Sobre los significados del término “výtržnictvî", cf. Havel, V. (1991), Disturbing the peace: A Conversation with Karel Hvížd'ala, trad. inglesa de P. Wilson, New York: Vintage, p. VIII.

41 Cf. al respecto, Lasaga Medina, José (2010), «El disidente político según Jan Patocka», en Circunstancia: revista de ciencias sociales del Instituto Universitario de Investigación Ortega y Gasset, año 8, n. 21. Disponible en: http://www.ortegaygasset.edu/publicaciones/circunstancia/ano-viii_-n-21—enero-2010/articulos/ el-disidente-politico-segun-jan-patoand-269-ka (fc 03/05/2018).

42 "Respondamos con toda claridad: la sumisión nunca ha llevado a mejorar la situación, sino a empeorarla. Cuanto mayor ha sido, y sea, el miedo y el servilismo, más atrevidos y arrogantes han sido, son y serán los poderosos. No hay ninguna manera de disminuir su presión más que si se tambalea su sentimiento de seguridad, si ven que la injusticia y la discriminación no quedan olvidadas, que las aguas no se cierran cubriendo todo lo que hacen": en Patočka, J. (2012), «Che cosa possiamo aspettarci da Charta 77?», en Id., La superciviltà e il suo conflitto interno. Scritti filosofico-politici, trad. ital. de F. Tava, Milano: Unicopli, p. 182. Para la traducción al castellano de esta cita, hemos utilizado la versión presente en Ortega Rodríguez, I. (2011) Fenomenología, Filosofía de la historia y Política en Jan Patočka, op. cit., pp. 380-381. 
compartía con aquella gente, agobiada por la mallas opresivas de un poder que pretendía dictar el sentido del mundo y de la misma existencia, había que reaccionar, respondiendo al llamamiento de la verdad -es decir, a esa apelación a la responsabilidad ${ }^{43}$ que procede del propio movimiento ontológico del mundo- y comportándose "con dignidad, sin temor, honestamente" 44 .

Dignidad, coraje, verdad. No ha sido tanto mediante la labor intelectual de profesor, o la difusión samizdat de sus Ensayos y sus cursos semiclandestinos, como sobre todo a través de una actitud consagrada al cuidado (y, si hubiera sido necesario, al sacrificio) de su propio punto de vista como ruptura y transgresión de lo instituido por lo que Patočka ha vinculado la figura del filósofo al deber de manifestar, en los pliegues de su propia vida, la disconformidad ética y política de una verdad que fuerza a transformar el modo propio de ser y que revela la perspectiva de un posible mundo "otro" - es decir, la "no-evidencia" y la "no-absolutez" de este mundo-.

Si la filosofía coincide con la actitud de un(os) individuo(s) que acepta(n) el reto de la política desde su óptica más opaca -es decir, con el punto de vista de quienes llegan a comprender la común precariedad de su vida, sin someterse a la coacción del miedo o a la indiferencia de la aceptación, y que reconocen en la figura conceptual de $\pi$ ó $\lambda \varepsilon \mu o \zeta$ el destello del vínculo entre filosofía y política, entre cuidado de sí y de los otros-, entonces creemos que es preciso entender los planteamientos éticos y políticos de Patočka sobre todo de acuerdo con lo que puede haber de propiamente "herético" en ellos. Una filosofía que, en cuanto perspectiva "problemática" capaz por primera vez (y cada vez de nuevo) de arrojar en el mundo la "pregunta radical" 45 por su sentido, aún hoy en día puede jugar un papel relevante, para Patočka, sólo si está completamente consagrada a un determinado modo de vida (y de muerte, como en el trágico caso del filósofo checo), a un compromiso y una "militancia ética"46 que, apuntando constitutivamente a la libertad, le permitan desempeñar la ocupación política más significativa:

El hombre espiritual no es evidentemente un político, no es un hombre político en el sentido común del término. No toma parte en el conflicto que divide al mundo. Pero es político en otro sentido, y puede serlo en la medida en que proyecta sobre la imagen de la sociedad y de todo lo que encuentra en torno suyo la no-evidencia de la realidad. ${ }^{47}$

\section{Referencias bibliográficas}

DÍAZ ÁLVAREZ, Jesús M. (1995), «J. Patocka: el sentido de la historia, el cuidado del alma y la comprensión de la modernidad»: en Investigaciones fenomenológicas: Anuario de la Sociedad Española de Fenomenología, n. 1, 1995, pp. 63-84.

43 Hay que tener en cuenta que también en la lengua checa, la palabra "responsabilidad", odpovědnost, remite al "responder", odpovědět.

44 Patočka, J. (2012), «Che cosa possiamo aspettarci da Charta 77?», en op. cit., p. 182.

45 Cf. Patočka, J. (2016), Ensayos heréticos sobre la filosofía de la historia, op. cit., 200.

46 Cf. Esquirol, J., M. (2011), Los filósofos contemporáneos y la técnica. De Ortega a Sloterdijk, op. cit., p. 88

47 Patočka, J. (1996), «El hombre espiritual y el intelectual», en op. cit., p. 188. 
DI MARTINO, Carmine (2017), «Philosophie et généalogie de l'histoire chez Jan Patočka», en Alter, 25/2017, pp. 173-192.

ESQUIROL, Josep M. (2000), «Tecnica e sacrificio in Jan Patočka», en Jervolino, Domenico (ed.), L'eredità filosofica di Jan Patočka. Napoli: Cuen, pp. 65-76.

ESQUIROL, Josep M. (2011), Los filósofos contemporáneos y la técnica. De Ortega a Sloterdijk, Barcelona: Gedisa.

FINDLAY, Edward F. (2002), Caring for the soul in a postmodern age. Albany: State University of New York Press.

HAVEL, Václav (1991), Disturbing the peace: A Conversation with Karel Hvižd'ala, trad. ingl. de Paul Wilson, New York: Vintage.

LASAGA MEDINA, José (2001), «Sobre la filosofía de la historia de Jan Patočka», en Investigaciones fenomenológicas: Anuario de la Sociedad Española de Fenomenología, n. 3, pp. 249-264.

LASAGA MEDINA, José (2010), «El disidente político según Jan Patocka», en Circunstancia: revista de ciencias sociales del Instituto Universitario de Investigación Ortega y Gasset, año 8, n. 21. Disponible en: http://www.ortegaygasset.edu/publicaciones/ circunstancia/ano-viii-_-n--21_-enero-2010/articulos/el-disidente-politico-segunjan-patoand-269-ka (fc 03/05/2018)

ORTEGA RODRÍGUEZ, Iván (2009), «Jan Patočka: fenomenología asubjetiva y filosofía herética de la Historia», en Arbor. Ciencia, Pensamiento y Cultura, n. 736 marzo-abril, pp. 339-353.

ORTEGA RODRÍGUEZ, Iván (2011), Fenomenología, Filosofía de la historia y Política en Jan Patočka, Madrid, Universidad Pontificia de Comillas.

PATOČKA, Jan (1983), Platon et l'Europe, trad. francesa de Erika Abrams, Lagrasse: Verdier.

PATOČKA, Jan (1992), «Was sind die Tschechen», en Id., Schriften zur tschechischen Kultur und Geschichte, Stuttgart: Klett-Cotta, pp. 29-106.

PATOČKA, Jan (1996), «El hombre espiritual y el intelectual», en Nombres. Revista de Filosofía, VI, n. 8-9, trad. de Diego Tatián, pp. 175-188.

PATOČKA, Jan (2003), Socrate . Lezioni di filosofia antica, trad. italiana de Giuseppe Girgenti y Martin Cajthalm (ed. bilingüe checo-italiano), Milano: Bompiani.

PATOČKA, Jan (2004), «¿Qué -es la existencia?», en Id., El movimiento de la existencia humana, trad. de Teresa Padilla, Jesús M. Ayuso y Agustín Serrano de Haro, Madrid: Encuentro, pp. 57-83.

PATOČKA, Jan (2007), «Reflexiones sobre Europa», en: Id., Libertad y sacrificio, trad. de Iván Ortega Rodríguez, Salamanca: Sígueme, pp. 187-220.

PATOČKA, Jan (2012), «Che cosa possiamo aspettarci da Charta 77?», en Id., La superciviltà e il suo conflitto interno. Scritti filosofico-politici, trad. ital. de Ferdinando Tava, Milano: Unicopli, pp. 181-186.

PATOČKA, Jan (2016), Ensayos heréticos sobre la filosofía de la historia, trad. de Iván Ortega Rodríguez, Madrid: Encuentro.

RICOEUR, Paul (2016), «Prefacio», en PATOČKA, Jan, Ensayos heréticos sobre la filosofía de la historia, trad. de Iván Ortega Rodríguez, Madrid: Encuentro, pp 17-27. 
SERRANO DE HARO MARTÍNEZ, Agustín (2004), «La idea de la solidaridad de los conmovidos en la obra de Jan Patocka», en Villar Ezcurra, Alicia; García-Baró López, Miguel (eds.), Pensar la solidaridad, Madrid: Universidad Pontificia Comillas, pp. $367-380$.

TASSIN, Etienne (1992), «Monde naturel et communauté politique: la question du sol», en Richir, Marc; Tassin, Etienne (eds.), Ján Patoc `ka: philosophie, phénoménologie, politique. Grenoble: Millon, pp. 167-187. 
